\title{
Improving vibration perception in a patient with type 2 diabetes and sensory peripheral neuropathy
}

\begin{tabular}{|c|c|}
\hline \multicolumn{2}{|c|}{$\begin{array}{l}\text { Authors: } \\
\text { Liezel Ennion }{ }^{1} \text { (D) } \\
\text { Juha Hijmans }{ }^{2}\end{array}$} \\
\hline \multicolumn{2}{|c|}{$\begin{array}{l}\text { Affiliations: } \\
{ }^{1} \text { Department of } \\
\text { Physiotherapy, University } \\
\text { of the Western Cape, } \\
\text { Cape Town, South Africa }\end{array}$} \\
\hline \multicolumn{2}{|c|}{$\begin{array}{l}{ }^{2} \text { University of Groningen, } \\
\text { University Medical Center } \\
\text { Groningen, Department of } \\
\text { Rehabilitation Medicine, } \\
\text { Groningen, the Netherlands }\end{array}$} \\
\hline \multicolumn{2}{|c|}{$\begin{array}{l}\text { Corresponding author: } \\
\text { Liezel Ennion, } \\
\text { liezel.ennion@gmail.com }\end{array}$} \\
\hline \multicolumn{2}{|c|}{$\begin{array}{l}\text { Dates: } \\
\text { Received: } 19 \text { Sept. } 2018 \\
\text { Accepted: } 31 \text { May } 2019 \\
\text { Published: } 25 \text { July } 2019\end{array}$} \\
\hline \multicolumn{2}{|c|}{$\begin{array}{l}\text { How to cite this article: } \\
\text { Ennion, L. \& Hijmans, J., } \\
\text { 2019, 'Improving vibration } \\
\text { perception in a patient with } \\
\text { type } 2 \text { diabetes and sensory } \\
\text { peripheral neuropathy', } \\
\text { South African Journal of } \\
\text { Physiotherapy 75(1), } \\
\text { a602. https://doi.org/ } \\
\text { 10.4102/sajp.v75i1.602 }\end{array}$} \\
\hline \multicolumn{2}{|c|}{$\begin{array}{l}\text { Copyright: } \\
\text { (C) 2019. The Authors. } \\
\text { Licensee: AOSIS. This work } \\
\text { is licensed under the } \\
\text { Creative Commons } \\
\text { Attribution License. }\end{array}$} \\
\hline \multicolumn{2}{|l|}{ Read online: } \\
\hline 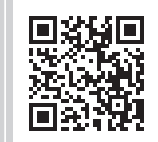 & $\begin{array}{l}\text { Scan this QR } \\
\text { code with your } \\
\text { smart phone or } \\
\text { mobile device } \\
\text { to read online. }\end{array}$ \\
\hline
\end{tabular}

Introduction: Diabetes mellitus (DM) and its related sensory peripheral neuropathy (SPN) are the biggest risk factors for foot ulcer formation and lower limb amputation. Reduced vibration perception results in less sensitivity to pressure and is a known risk factor for diabetic foot ulcers. Improving vibration perception in the feet of people with SPN could be protective against foot ulcers. The aim of this study was to determine if a therapeutic vibrating insole, used for 35 consecutive days, could improve vibration perception in a patient with type $2 \mathrm{DM}$.

Patient presentation: The patient was a 63 year-old male with a medical history of peripheral vascular disease, controlled hypertension, hyperlipidaemia, artherosclerosis and SPN secondary to controlled type 2 diabetes.

Management and outcome: The patient used the insoles for $20 \mathrm{~min}$ a day for 35 consecutive days. Vibration perception thresholds were measured four times in total: once at baseline, immediately post intervention, 1 month and 10 months later. Vibration perception threshold decreased with an average of $22 \mathrm{~V}$ (range $6 \mathrm{~V}-34 \mathrm{~V}$ ) dependant on the tested location and time after intervention. The improvement remained after 1 and 10 months.

Conclusion: The use of a vibrating insole as a therapeutic device improved this patient's perception of vibration in his feet. Clinically, vibrating insoles potentially might reduce the risk for ulcer formation and subsequent lower limb amputation in patients with DM and SPN.

Clinical implications: Using a vibrating insole therapeutically, can potentially improve the perception of vibration and pressure in patients with sensory peripheral neuropathy secondary to type 2 diabetes mellitus. Improved vibration perception might reduce the risk for diabetic ulcer formation and subsequent lower limb amputation.

Keywords: Diabetes type 2; foot ulcers; intervention; vibrating insoles; Stochastic Resonance.

\section{Introduction}

Sensory peripheral neuropathy (SPN) is a common complication of diabetes mellitus (DM) (Kärvestedt et al. 2011). The loss of vibration sensation is a major risk factor for developing foot ulcers (Ko \& Cha 2012). Foot ulcer, in turn, is the biggest risk factor for lower limb amputation in patients with DM (Lipsky et al. 2011).

Repetitive sensory stimulation (RSS) has been shown to improve sensory perception in patients following stroke, and children with autism, but has not been studied in type 2 diabetic patients with SPN. The brain is known to adapt in response to certain deficits or sensori-motor inputs (Makin et al. 2013). Repeated exposure to stimuli results in changes in the awareness of the sensory system, and its ability to identify certain inputs (Sathian et al. 2013). These changes in acuity are commonly referred to as perceptual learning. The potential application of perceptual learning and adaptations in the brain for rehabilitation is vast.

The same mechanoreceptor in the skin, the Pacinian corpuscle which is responsible for detecting pressure, is also responsible for detecting vibration (as it is in essence pressure applied to the skin). If an intervention aimed at improving a patient with SPN's ability to perceive vibration is successful, it could be used therapeutically to potentially prevent ulcer formation. At an impairment level, diabetic foot ulcers cause pain, which negatively affects patients' mobility and balance. Decreased mobility may also worsen the already impaired circulation and prolong ulcer healing time in the diabetic population, increasing the risk of wound infection and lower limb amputation. Challenges with mobility also limit the activities of daily living (social and economic) in which the person can participate. In turn a loss of independence in mobility can lead to psychological problems such as anxiety and depression, decreased participation in society and ultimately social exclusion. Preventing the formation of diabetic foot ulcers may prevent disability 
across the whole spectrum of impairment, activity and participation and may lead to improved quality of life for persons with DM.

\section{Ethical considerations}

Ethical clearance was obtained from the University of the Western Cape's Biomedical research ethics committee (BM 16_3_23). Written informed consent was obtained from the participant prior to data collection.

\section{Patient presentation}

A 63-year-old retired male with a medical history of peripheral vascular disease, controlled hypertension, hyperlipidaemia, atherosclerosis and controlled type 2 diabetes mellitus participated in this single-case study. He was diagnosed with diabetes mellitus and peripheral vascular disease 15 years ago. He suffered a transient ischaemic attack at the time, and his carotid disease was discovered. It resulted in a left-sided carotid endarterectomy. The participant had artherosclerosis of both the right and left external iliac arteries, with approximately $90 \%$ occlusion, confirmed via angiogram (right more occluded than left). Chronic medication included Diaphage $1 \mathrm{~g}$ twice a day, Ciplazar $50 \mathrm{mg}$, Lomanor $5 \mathrm{mg}$, Simvastatin $4 \mathrm{mg}$, Disprin and Dopaquel $200 \mathrm{mg}$ twice a day. The participant had been a smoker for the past 50 years and currently smoked 10 to 15 pipes of tobacco per day. He did not consume any alcohol and had been diagnosed with sensory peripheral neuropathy in both feet secondary to type 2 DM 3 years prior to this study.

The presence of SPN was confirmed with a Bio-Thesiometer (Model PVD-LP). The Bio-Thesiometer is calibrated and considered as the gold standard for diagnosing SPN. The Bio-Thesiometer is considered as the gold standard to detect SPN because of its strong predictive value for diabetic foot ulceration. A vibratory perception threshold (VPT) of $15 \mathrm{~V}$ and lower is considered normal or low risk (2.9\%) for foot ulceration, while a VPT of $>25 \mathrm{~V}$ has an increased risk of 19.8\% for diabetic ulcers (Young et al. 1994).

\section{Management}

A vibrating insole prototype that delivers a mechanical noise signal at a varied frequency was used as the RSS intervention in this case study. This prototype was similar to the initially developed prototype for a study to enhance balance in patients with peripheral neuropathy. The technical specifications of the insole are described in Hijmans et al. (2007). The participant was requested to wear the insole daily, inside a comfortable shoe in a sitting position. The participant kept a daily log of the time and wore the insole for an average of 20 minutes per day for 35 consecutive days. A log was kept to document the duration of daily wear, in case this varied from the given instructions. The participant continued with his normal activities of daily living in every other aspect. He did not exercise and was largely sedentary due to claudication pain in his legs when he walked more than $100 \mathrm{~m}$ at a time. He had been following a

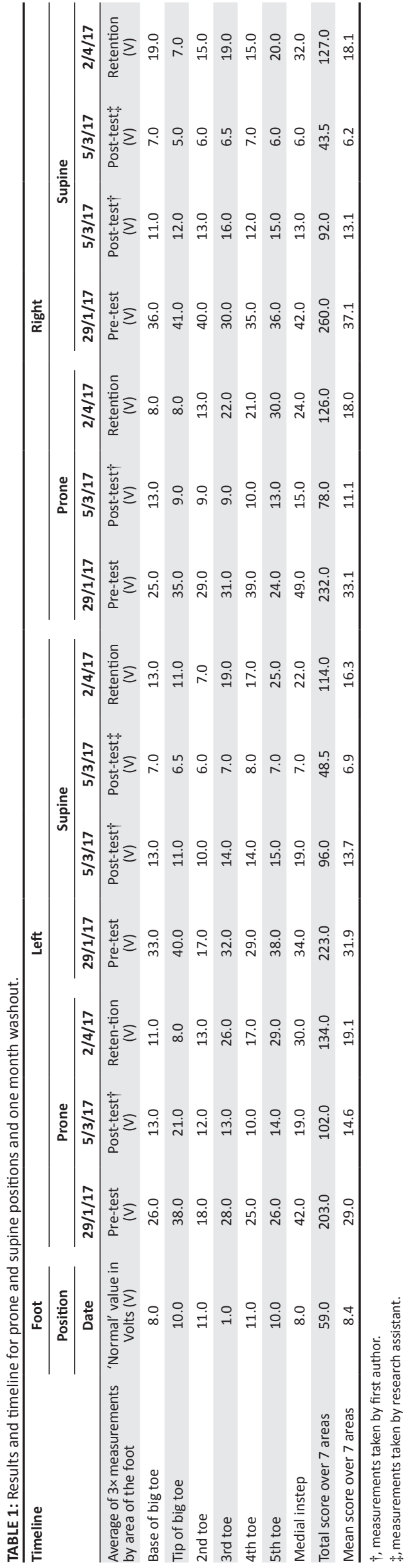


low-carbohydrate (Banting) diet for the previous 4 years. No other interventions or medication (apart from his chronic medications listed above) was administered during this period.

A Bio-Thesiometer (Model PVD-LP) was used to establish the participant's VPT score in volts at baseline. Measures were taken from seven points on the foot. Normal values for each reading are provided in the manual for the Bio-Thesiometer (Table 1). Measurements were repeated at 35 days and 10 months by both the first author and a research assistant after the intervention was initiated to account for any bias.

The baseline measurement of the participant's VPT with the Bio-Thesiometer indicated a mean score of $31 \mathrm{~V}$ (unit of measurement for the Bio-Thesiometer) across seven points of both feet in the prone position and a $34.5 \mathrm{~V}$ in the supine position. The head of the Bio-Thesiometer was firmly applied to the point of contact on the patient's foot, and the patient was asked to close his eyes while the first author slowly increased the amplitude of the vibration. The patient then told the first author or research assistant as soon as he detected the vibration, and the first author or research assistant then documented the corresponding reading in volts from the Bio-Thesiometer. Measurements at each point were repeated three times to ensure reliability, and the average was calculated.

\section{Results}

A clinically important $(19.7 \mathrm{~V})$ reduction in the VPT was determined between pre-intervention, mean $32.8 \mathrm{~V}( \pm 7.1)$, and post-intervention, mean $13.1 \mathrm{~V}( \pm 2.8)$, scores across the seven points (by the first author). The findings are considered clinically important because the patient no longer fits the criteria for SPN (VPT > 25 V) (Peters et al. 2001). For every 1 $\mathrm{V}$ increase in VPT, a $5.6 \%$ increase in chance of ulceration is reported (Abbott et al. 1998). Conversely, for every $1 \mathrm{~V}$ reduction in VPT, the risk for ulceration should be diminished by $5.6 \%$. Using this formula, the patient should thus have almost no risk for foot ulceration. There was an increase of $4.8 \mathrm{~V}$, mean $17.9 \mathrm{~V}( \pm 7.9)$, in the VPT after the washout period of one month, but this change was not clinically important as the patient was still under the threshold of $20 \mathrm{~V}$, which is considered an increased risk for foot ulceration.

No clinical differences were detected between the prone and supine positions in the initial tests, or between the left and right foot for any of the measurements; so, values reported are for the left foot as assessed by the first author in the supine position (Figure 1). Subsequent measures were taken only in the supine position as the participant reported being more comfortable in supine. After 10 months (Table 2), the VPT was further reduced by $23.2 \mathrm{~V}$, mean $9.6 \mathrm{~V}( \pm 3.2)$, in the supine position. Clinically, the participant reported an overall general improvement in sensation in his feet. He mentioned being able to 'feel the texture of the carpet' under his feet which he was not able to feel before the intervention. He also mentioned an overall increased sensitivity in his entire foot and more stability while walking.

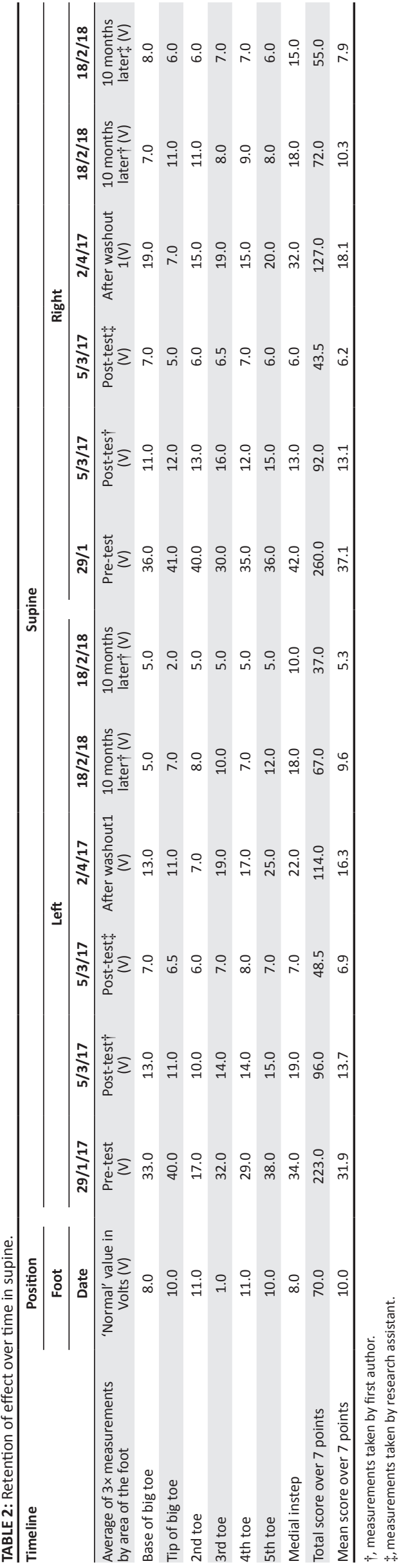




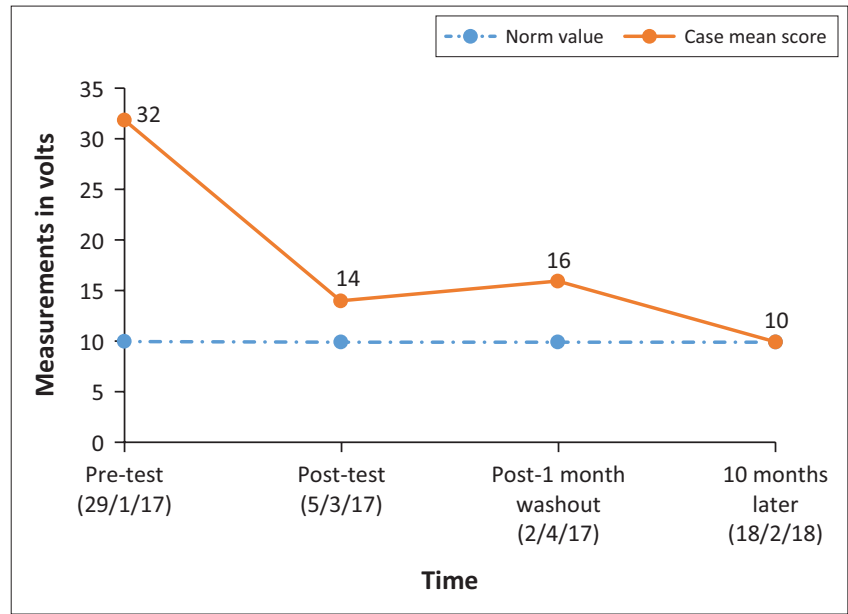

FIGURE 1: Supine position: change in mean vibratory perception threshold scores (volts) over time.

The retention of the effect is new information and has not been investigated or documented before. It seems that in this case, the therapeutic use of vibrating insoles has reversed one of the symptoms of peripheral neuropathy.

\section{Conclusion}

This case study demonstrates a clinical reduction in VPT for a patient with SPN after using a mechanical noise vibrating insole intervention for a period of 20 minutes per day for 35 days. The results from this study may thus have a considerable protecting effect for ulceration.

Owing to the nature of single-case studies, the findings of this study cannot be generalised to the diabetic population but can be used to stimulate further research and discussion on the topic. The physiological mechanism of how this intervention reduced VPT and why the effect is being retained in this case study cannot be explained. It could potentially be as a result of increased sensitivity of the mechanoreceptors on the plantar aspect of the feet and a resultant increase in corticomuscular synchronisation (Trenado et al. 2014). The retention of the effect could point to increased corticomuscular coherence or neuroplastic changes. This effect is, however, currently being investigated with a bigger cohort of patients and in a subsequent functional magnetic resonance imaging study.

The findings of this single-case study are relevant and clinically important as they potentially could result in a reduced risk for ulcer formation in patients with DM and potentially reduce the risk of lower limb amputation. A decreased risk for diabetic foot ulcers can contribute to the decrease of the associated disability by maintaining functional mobility for longer duration. Improved mobility will result in participation in daily and socio-economic activities, and inclusion in society, ultimately resulting in improved quality of life.

\section{Acknowledgements}

The authors would like to acknowledge and thank the patient who was willing to participate in this study.

\section{Competing interests}

The authors have declared that no competing interests exist.

\section{Authors' contributions}

L.E. conceptualised the study, collected the data and drafted the case report. J.H. provided technical advice on the use of the insoles and reviewed the final article.

\section{Funding}

This study was funded by the University of the Western Cape's Early Career Research Support programme.

\section{Data availability statement}

All the data from this case study are available and presented in the text.

\section{Disclaimer}

The views and opinions expressed in this article are those of the authors and do not necessarily reflect the official policy or position of any affiliated agency of the authors.

\section{References}

Abbott, C.A., Vlleikyte, L., Williamson, S., Carrington, A.L. \& Boulton, A.J.M., 1998 'Multicenter study of the incidence of and predictive risk factors for Diabetic Neuropathic foot ulceration', Diabetes Care 1998 21(7), 1071-1075. https://doi. org/10.2337/diacare.21.7.1071

Hijmans, J.M., Geertzen, J.H.B., Schokker, B. \& Postema, K., 2007, 'Development of vibrating insoles', International Journal of Rehabilitation Research 30, 343-345. https://doi.org/10.1097/MRR.0b013e3282f14469

Kärvestedt, L., Mårtensson, E., Grilla, V., Elofsson, S., Von Wendt, G., Hamsten, A. et al., 2011, 'The prevalence of peripheral neuropathy in a population-based study of patients with type 2 diabetes in Sweden'. Journal of Diabetes and its Complications 25(2), 97-106. https://doi.org/10.1016/j.jdiacomp.2010.04.001

Ko, S.H. \& Cha, B.Y., 2012, 'Diabetic peripheral neuropathy in type 2 diabetes mellitus in Korea'. Diabetes \& Metabolism Journal 36, 6-12. https://doi.org/10.4093/ dmj.2012.36.1.6

Lipsky, B.A., Weigelt, J.A., Sun, X., Johannes, R.S., Derby, K.G. \& Tabak, Y.P., 2011 , 'Developing and validating a risk score for lower-extremity amputation in patients hospitalized for a diabetic foot infection', Diabetes Care 34(8), 1695-1700. https:// doi.org/10.2337/dc11-0331

Makin, T.R., Cramer, A.O., Scholz, J., Hahamy, A., Henderson Slater, D., Tracey, I. et al. 2013, 'Deprivation-related and use-dependent plasticity go hand in hand', Elife 2 e01273, viewed 05 May 2018, from http://www.ncbi.nlm.nih.gov/pmc/articles/ PMC3823186/pdf/elife01273.pdf.

Peters, E.J. \& Lavery, L.A., International Working Group on the Diabetic Foot, 2001 'Effectiveness of the diabetic foot risk classification system of the International Working Group on the Diabetic Foot'. Diabetes Care 24, 1442-1447. https://doi. org/10.2337/diacare.24.8.1442

Sathian, K., Deshpande, G. \& Stilla, R., 2013, 'Neural changes with tactile learning reflect decision-level reweighting of perceptual readout', Journal of Neuroscience 33(12), 5387-5398. https://doi.org/10.1523/JNEUROSCI.3482-12.2013

Trenado, C., Mendez-Balbuena, I., Manjarrez, E., Huethe, F., Schulte-Mönting, J., Feige, B. et al., 2014, 'Enhanced corticomuscular coherence by external stochastic noise' Frontiers in Human Neuroscience 8, 325. https://doi.org/10.3389/fnhum.2014.00325

Young, M.J., Breddy, J.L., Veves, A. \& Boulton, A.J.M., 1994, 'The prediction of diabetic neuropathic foot ulceration using vibration perception thresholds: A prospective study', Diabetes Care 17(6), 557-560. https://doi.org/10.2337/diacare.17.6.557 